\section{Response: Straying and Spaying: \\ What Do Cats Care About?}

\section{William O. Stephens Creighton University}

In her paper, "What Do Animals Care About?," LillyMarlene Russow argues for two theses. The first is that the arguments of Frey and Leahy fail to establish that animals do not have interests in a morally relevant sense. I think she is successful in defending this thesis. Less convincing is her second thesis, namely, that we are better off focusing on the question of what animals care about than continuing to speak of the interests that animals have. While Russow's criticisms of behaviorism are persuasive, she offers no compelling grounds to accept her suggestion that computers might well have desires. Since computers lack nervous systems and are not conative organisms, it seems implausible to think they have desires. Russow is also too casual in assuming that we can simply set aside extreme skepticism. She gives no hint of how this can be done in a philosophically adequate way. But the main question I want to focus on is: What do specific nonhuman animals specifically care about?

Let me begin by reflecting in some detail on Russow's claim that "The undeniable fact is that experienced observers can tell quite well when an animal is happy." I am trained as a professional philosopher and not as a professional cat-handler, but I do fancy myself an experienced observer of feline behavior since I have lived with two cats for about thirteen years of my life. I think that for any investigation of what animals care about, it is important to address specific, concrete examples of what

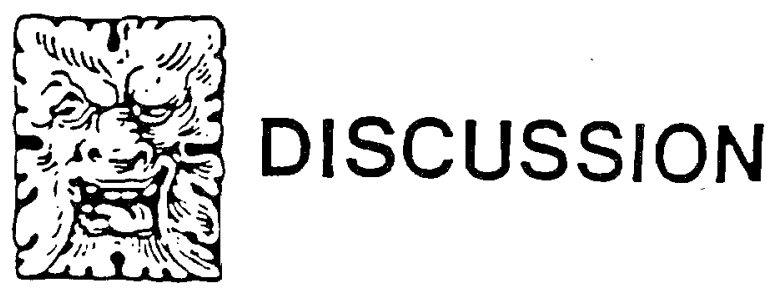

particular animals may or may not care about. So, now I will consider what sorts of things my cats care about.

I decided to adopt a pair of kittens about four years ago. I thought it better to have two cats rather than one since I believed that a solitary cat would be less happy than a cat with a playmate. I agree with Russow that using words like "happy" and "content" to describe nonhuman animal behavior is, though scientifically unmeasurable, still philosophically justifiable. When I went to the Omaha Humane Society to see a litter of six-week-old kittens they had told me about over the phone, I was shown a litter of four kittens, three females and a male. Since I thought I could not easily manage four growing cats, I decided to adopt the three females while hoping that someone else would adopt the male. Thus, my first decision was to separate the orphaned siblings. Did the three sisters care about being separated from their brother? All four kittens were mewing loudly at the time, which I interpreted as distress, but perhaps their distress was due to their uncomfortable surroundings at the Humane Society or the previous loss of their mother, and not their separation from their brother.

Soon after bringing the three kittens home, I tried to put small collars with their identification tags on them. They reacted by (frantically?) leaping about, arching their necks, and struggling to pull the collars off with their paws. I inferred from this behavior that they didn't much care for the collars, and so I promptly removed them. A week or two later, one of the kittens began to have diarnhea. My veterinarian diagnosed her as suffering from a gastro-intestinal infection, and he supplied me with medicine for her. Sadly, the medication failed to cure her ailment. Despite my efforts, she stopped eating entirely, became very weak in a short time, and died on a Sunday evening before I could take her to the vet the next morning. Had the unfortunate kitten stopped caring about food? Hours before she died, her two sisters huddled with her just as they had often done before when all three were healthy. Did the two surviving kittens care about their sister dying? I could not judge either way from their behavior since they neither attended closely to the dead kitten nor avoided it in any obvious way. They simply seemed to ignore it.

As is usually the case, the two cats, Bryseis and Chryseis, developed quite distinct personalities. Bryseis, the more athletic cat, exhibits a strong interest in exploring the basement, going outside, and drinking from sinks, the toilet, and the tub. Chryseis, in contrast, 
seems not to care about the basement, the out-of-doors, or drinking from places other than her water bowl; Chryseis cares much more about being fed canned rather than dry cat food. Do I have a moral obligation to let Bryseis go outside? Making them wear collars as kittens seemed to make them quite unhappy. So, since Bryseis still remains collarless and untagged, I am reluctant to let her become an "outdoor" cat. If I allowed her to roam free in my neighborhood, I would expose her to the risk of fights with other animals, serious injury, or even death from being struck by an automobile. Am I justified in seriously restricting her liberty as I do? Cats are predators, after all, and her telos as a cat certainly includes sniffing outdoor scents, stalking birds, chasing insects, and hunting small herbivores. Therefore, she might well be more content freely exploring the outdoor environment for hours every day than staying indoors all but a few minutes every week when I closely supervise her limited excursions outdoors. Does Bryseis care about living a long, safe life indoors? Or would she be much happier roaming the neighborhood unimpeded by my paternalistic, protectionist interference? Would she return home if I let her outside on her own? And if she did not, would she be happier as a stray? How am I to interpret her behavior so as reasonably to judge what would make her happiest? Would there be, to use Russow's words, "a high degree of intersubjective agreement, at least among skilled, trained, experienced practitioners" about what would most contribute to Bryseis' happiness?

Consider another behavior. My cats have developed the all too common "vice" of clawing the furniture, despite my conscientious efforts to trim their claws regularly. If I decided never to allow them outside on their own, then they would never need their claws to defend themselves from attack by hostile animals. Do cats care about being declawed?

Another element of the telos of cats is surely to reproduce. Do female cats care about being spayed? Are feline mothers who nurture kittens happier than their spayed sisters? Do male cats care about being neutered? Are promiscuous tomcats happier than their neutered, more docile brothers? Or do we have a paternalistic justification for spaying and neutering dogs and cats in order to minimize the number, and the usual suffering, of strays?

Russow suggests that "a definitive criterion of what we care about (as opposed to what we think we care about) is that it contributes to our happiness or alleviates our unhappiness." Given the behavior my cats exhibit when I am away from home for long periods of time, surely they would be happier, and not just think themselves happier, were I to spend more time at home with them. Does this suffice to establish that I have a prima facie duty to spend more time at home with my cats? Russow proposes the following definition: "S cares about $\mathrm{O}$ if and only if $\mathrm{S}$ directly desires $\mathrm{O}$, and getting or achieving O contributes to $S$ 's happiness."

This definition seems inadequate for two reasons. First, while it may seem to capture our ordinary concept of caring about inanimate objects, I think it fails to describe our ordinary concept of caring about other sentient subjects. Many humans, and perhaps many intelligent nonhuman animals as well, care about other sentient beings for their own sakes, and not only because the company of those subjects contributes to the happiness of the individual who is doing the caring. I offer the following definition of intersubjective caring:

$S_{1}$ cares about $S_{2}$ if and only if $S_{1}$ desires to promote the happiness or well-being of $S_{2}$, whether $S_{1}$ and $S_{2}$ are conspecifics or sentient beings of different species.

Let us return to my stock example. Do my cats care about each other (and me) in the same sort of way that they care about being fed canned cat food and having a clean litterbox? If so, then when they play with each other they care about each other the same sort of way they care about a paper clip or a pair of socks when they play with these things. I am not inclined to construe their caring about each other so narrowly. They exhibit reciprocal altruism when they groom each other. Such reciprocal altruism suggests to me that they may well care about each other's well-being to some extent. That is, Bryseis may well care about the subject Chryseis, an individual with her own well-being, rather than merely caring about the object Chryseis, a thing that contributes to Bryseis' happiness.

The second reason to hesitate accepting Russow's definition of "caring about" is that she is imposing it as a stipulative definition that does not, in fact, "accord well with our ordinary concept of caring about" even when "O" refers exclusively to objects. For example, I could on some occasion care about having some cheesecake. Later, after I find and eat a piece of cheesecake, I could well discover that having it did not make me happy but, rather, made me sad for failing to 
keep to my diet. It would be wrong to say in retrospect that I didn't really care about having the cheesecake in the first place. Rather, we should say I no longer care about having more cheesecake because, having committed dietary sin, I now care more about returning to my diet. In short, I do not see how Russow's distinction between "caring about" and "thinking we care about" does more work than the distinction between "taking an interest in" and "successfully promoting one's self-interest." To say that smokers take an interest in smoking, but smoking is not really in their selfinterest, strikes me as more in accord with our ordinary concepts than saying that smokers think they care about smoking, but do not really care, since smoking does not contribute to their long-term happiness. Similarly, to say that my cat Bryseis takes an interest in roaming free outside, but roaming free outside is not really in her self-interest, makes more sense to me than to say that Bryseis thinks she cares about roaming free outside, but she does not really care, since it probably endangers her long-term happiness.

Russow has made a decent attempt to advance the discussion of how best to talk about animals' interests, desires, and happiness. However, her proposed definition of "caring about" fails to mark the qualitative difference between caring about an object and caring about a subject and does not, in fact, accord well with our ordinary concept of caring about generally. Moreover, since Russow's discussion is deficient at the theoretical level on these points, its application to questions about specific animals-for example, whether housecats care about being allowed to stray outside, being spayed or neutered, etc.-is not promising.

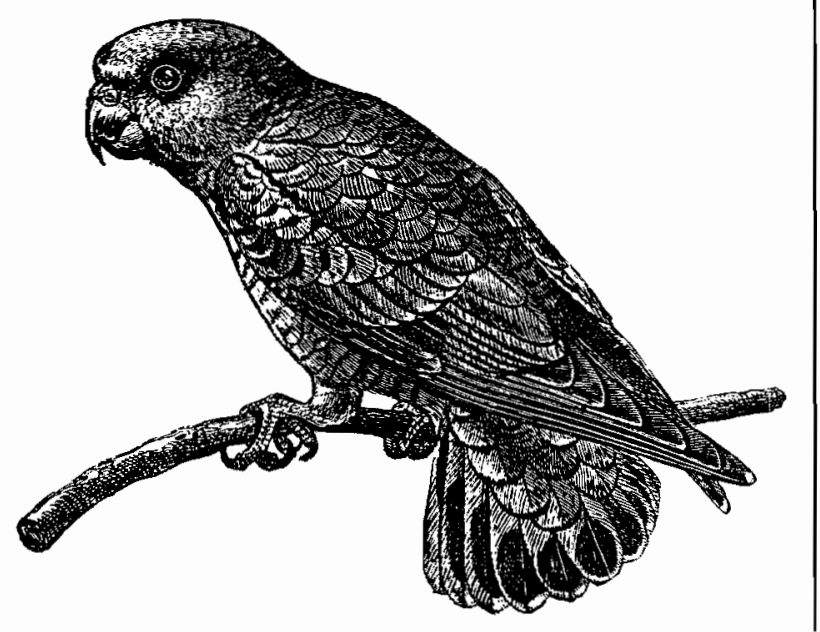

\section{Reply}

\section{Lilly-Marlene Russow Purdue University}

I could respond by answering Professor Stephens' specific questions about his cats: either offering a judgment about what they do and don't care about, or explaining what one would do to determine that. But that would fill up all the remaining time, and miss his deeper concerns. Instead, I'll say just a few words about two more general concerns that he raises, either explicitly or implicitly:

(1) how we can determine the object of intentional states, including caring, and

(2) why "caring about" is an improvement over talk about interests.

I take it that the philosophical issue underlying Stephens' questions about what his cats care about in specific incidents is the concern that there may be no legitimate way of answering these questions. The full answer to his concern would be too complicated to lay out in detail-not because he's asking about cats, but because specifying the object of any mental state is a complicated business. Nonetheless, I'll try to indicate some of the factors that should be involved.

First, sometimes de re specifications of mental states are the most appropriate ones. That is to say, we can say that Chryseis believes of Stephens that he is a source of food, without claiming or being committed to anything about how he is "represented." The same is true of other propositional attitudes, especially caring about. Thus, it is certainly reasonable, and perhaps even necessary, at times to read "Chryseis cares about Stephens" as a de re attitude.

Even if there is good reason to demand a de dicto account of a mental state, there still may be good

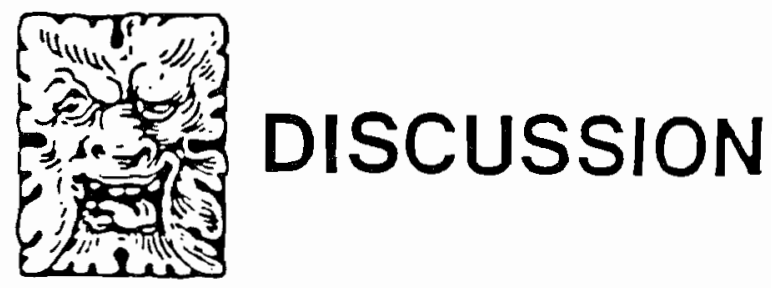

